\title{
Antigen receptor signaling induces MAP kinase-mediated phosphorylation and degradation of the BCL-6 transcription factor
}

\author{
Huifeng Niu, Bihui H. Ye, and Riccardo DallaFavera' \\ Departments of Pathology and Genetics and Development, Columbia University, N ew York, N ew York 10032 USA
}

The bcl-6 proto-oncogene encodes a POZ/zinc finger transcriptional repressor expressed in germinal center (GC) B and T cells and required for GC formation and antibody affinity maturation. Deregulation of bcl-6 expression by chromosomal rearrangements and point mutations of the bcl-6 promoter region are implicated in the pathogenesis of B-cell lymphoma. The signals regulating bcl-6 expression are not known. Here we show that antigen receptor activation leads to BCL-6 phosphorylation by mitogen-activated protein kinase (MAPK). Phosphorylation, in tum, targets BCL-6 for rapid degradation by the ubiquitin/proteasome pathway. These findings indicate that BCL-6 expression is directly controlled by the antigen receptor via MAPK activation. This signaling pathway may be crucial for the control of B-cell differentiation and antibody response and has implications for the regulation of other $\mathrm{POZ} /$ zinc finger transcription factors in other tissues.

[Key Words: BCL-6; BCR signaling; M AP kinase; POZ/zinc finger proteins; ubiquitin-proteasome]

Received March 12, 1998; revised version accepted M ay 4, 1998.

The bcl-6 proto-oncogene was identified by virtue of its involvement in chromosomal translocations in diffuse large cell lymphoma (DLCL), the most common form of non-Hodgkin's Iymphoma (NHL) (Baron et al. 1993; Kerckaert et al. 1993; Ye et al. 1993; Miki et al. 1994). Subsequent studies have demonstrated that rearrangements of the bcl- 6 gene can be found in $30 \%-40 \%$ of DLCL and in a minority $(5 \%-10 \%)$ of follicular lymphoma (FL) (Bastard et al. 1994; LoCoco et al. 1994; Otsuki et al. 1995). These rearrangements juxtapose heterologous promoters, derived from other chromosomes, to the bcl- 6 coding domain, causing its deregulated expression by a mechanism called promoter substitution (Ye et al. 1995; Chen et al. 1998). The 5' noncoding region of the bcl- 6 gene can also be altered by somatic point mutations that are detectable, independent of rearrangements, in 70\% DLCL, 45\% FL, and AIDS-associated N HL (Migliazza et al. 1995; Gaidano et al. 1997). Taken together, rearrangements and mutations of the bcl- 6 promoter region represent the most frequent genetic alteration in human B-cell malignancies, suggesting they may be important for tumorigenesis (Dalla-Favera et al. 1996).

The BCL- 6 protein is a nuclear phosphoprotein bel onging to the POZ/zinc finger (ZF) family of transcription factors (Kerckaert et al. 1993; Ye et al. 1993; Miki et al.

${ }^{1}$ Corresponding author.

E-MAIL RD10@columbiaedu; FAX (212) 305-5498.
1994). It contains six Krüppel-type carboxy-terminal zinc finger (ZF) motifs that have been shown to recognize specific DN A sequences in vitro (Chang et al. 1996; Seyfert et al. 1996) and an amino-terminal POZ motif (Albagli et al. 1995) shared by various ZF molecules including the Drosophila developmental regulators Tramtrack and Broad-complex (Harrison and Travers 1990; DiBello et al. 1991), the human KUP (Chardin et al. 1991), ZID (Bardwell and Treisman 1994), and PLZF (Chen et al. 1993) proteins as well as by POX viruses (Koonin et al. 1992) and the actin-binding Drosophila oocyte protein Kelch (Xue and Cooley 1993). BCL-6 functions as a potent transcriptional repressor by binding to its DNA target sequence (Deweindt et al. 1995; Chang et al. 1996; Seyfert et al. 1996).

BCL-6 is an important regulator of Iymphoid devel opment and function. In the B-cell lineage, the BCL- 6 protein is found only in $B$ cells within germinal centers (GC), but not in pre-B cells or in differentiated progeny such as plasma cells. In the T-cell lineage, BCL- 6 protein is detectable in cortical thymocytes and in $\mathrm{CD} 4^{+} \mathrm{T}$ cells within GC as well as scattered in the perifollicular area (Cattoretti et al. 1995; Onizuka et al. 1995; Allman et al. 1996). Mice deficient in BCL-6 display normal B-cell, Tcell, and lymphoid organ development but have a selective defect in $\mathrm{T}$-cell-dependent antibody responses because of the inability of follicular B cells to proliferate and form GC (Dent et al. 1997; Ye et al. 1997). In addition, BCL-6-deficient mice develop an inflammatory re- 
sponse in multiple organs characterized by infiltration of eosinophils and IgE-bearing B Iymphocytes typical of a Th2-mediated inflammatory response. These phenotypes may be explained by the ability of BCL- 6 to bind the ST AT-6 DN A-binding site and repress transcription activated by STAT-6, the main nuclear effector of IL-4 signaling (Dent et al. 1997; Ye et al. 1997).

The expression and requirement of BCL-6 during GC formation and its alteration in GC-derived Iymphoma suggest that BCL-6 may be a key regulator of GC development and antibody-mediated immune response. Toward the elucidation of the signals that regulate GC expression, we report here the identification of a signaling pathway by which B-cell antigen receptor directly regulates BCL-6 stability.

\section{Results}

Recent studies have shown that the BCL- 6 protein is phosphorylated at multiple sites by mitogen-activated protein kinases (MAPKs), ERK-1 and ERK-2, but not by Jun amino-terminal kinase (JNK) in vitro and in vivo (Moriyama et al. 1997). The results shown in Figure 1 confirm that purified recombinant MAPK (ERK-2) can phosphorylate GST-BCL-6 fusion proteins in vitro. The phosphorylation targets were mapped to the amino-terminal half of the molecule since a carboxy-terminal deletion mutant (GST-BCL-6 $\Delta \mathrm{ZF}$ ) could be phosphorylated at levels comparable to the wild-type molecule, whereas an amino-terminal deletion mutant (GST-BCL-6ZF) could not be phosphorylated at all (Fig. 1B). Because BCL-6 contains two perfect consensus sites (PXSP) for MAPK-mediated phosphorylation (see Fig. 1A), we generated two mutants (BCL- $6_{\mathrm{Ala} \text { a333 }}$ and BCL-6 $\left.6_{\mathrm{Ala333,343}}\right)$ in which one or both of these sites were al tered by substituting serines with alanines. These two mutants were phosphorylated at much lower levels than wild-type BCL-6, with BCL-6 Ala333,343 displaying the lowest levels
(Fig. 1C). This result indicates that the $\mathrm{Ser}_{333}$ and $\mathrm{Ser}_{343}$ residues represent a si gnificant fraction, al though not all, of the BCL-6 phosphorylation target sites. The residual low level of phosphorylation is consistent with the existence of additional potential MAPK target sequences (SP) clustered within the central domain of the BCL-6 molecule.

\section{MAPK-mediated phosphorylation induces BCL-6 degradation}

To determine the effects of MAPK-mediated phosphorylation on bcl-6 expression and function, 293T cells (which do not express endogenous BCL-6) were cotransfected with vectors expressing BCL-6, and a MEK (MAP/ ERK kinase) mutant (MEK-2E) that functions as a constitutively active MAPK kinase ( $\mathrm{Y}$ an and Templeton 1994). Western blot analysis of transfected cell extracts showed that MEK-2E expression (documented by increased ERK2 kinase activity of MEK-2E transfected cell extracts in solid-phase kinase assays in vitro; Fig. 2A, bottom) induced a dramatic reduction of BCL-6, but not ERK, levels (Fig. 2A, top and middle). The observed reduction in BCL-6 protein levels was dependent upon the phosphorylation activity of MEK-2E, since it did not occur when a vector expressing inactive MEK was cotransfected with bcl-6 (Fig. 2B). N orthern blot analysis of the same transfected cells showed that the reduction in BCL- 6 protein level s were not caused by decreased bcl- 6 mRN A levels (Fig. 2B, bottom). Furthermore, the MEK$2 \mathrm{E}$-induced decrease in BCL-6 levels was dependent on target phosphorylation, as the partial phosphorylationresistant mutant $\mathrm{BCL}-6_{\mathrm{Ala333,343}}$ was partially resistant to MEK-2E-mediated down-regulation (Fig. 2C). These results indicate that the $\mathrm{MEK}-2 \mathrm{E}$-induced decrease in BCL-6 levels is not caused by decreased gene transcription or protein synthesis, but rather by decreased protein stability.

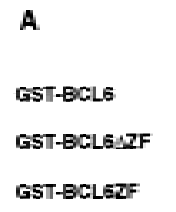

Figure 1. Phosphorylation of BCL-6 by ERK2 in vitro: (A) Schematic representation of wild-type and mutant GST-BCL-6 fusion proteins. $\left(^{*}\right)$ Serines within MAPK phosphorylation sites (PXSP). (ZF) Zinc finger domain. (B) ERK2 kinase assays using GST-BCL-6 wild-type and deletion mutants as substrates in the presence of $\left[\gamma^{-}{ }^{32}\right.$ P]ATP. (C) (Top) ERK2 kinase assay for wild-type (WT) or mutant (Ala333; Ala333,343) GST-BCL6 2 ZF proteins. (Bottom) Coomassie blue staining of the gel shown at top demonstrating comparable amounts of proteins loaded. Molecular mass markers are shown at left.
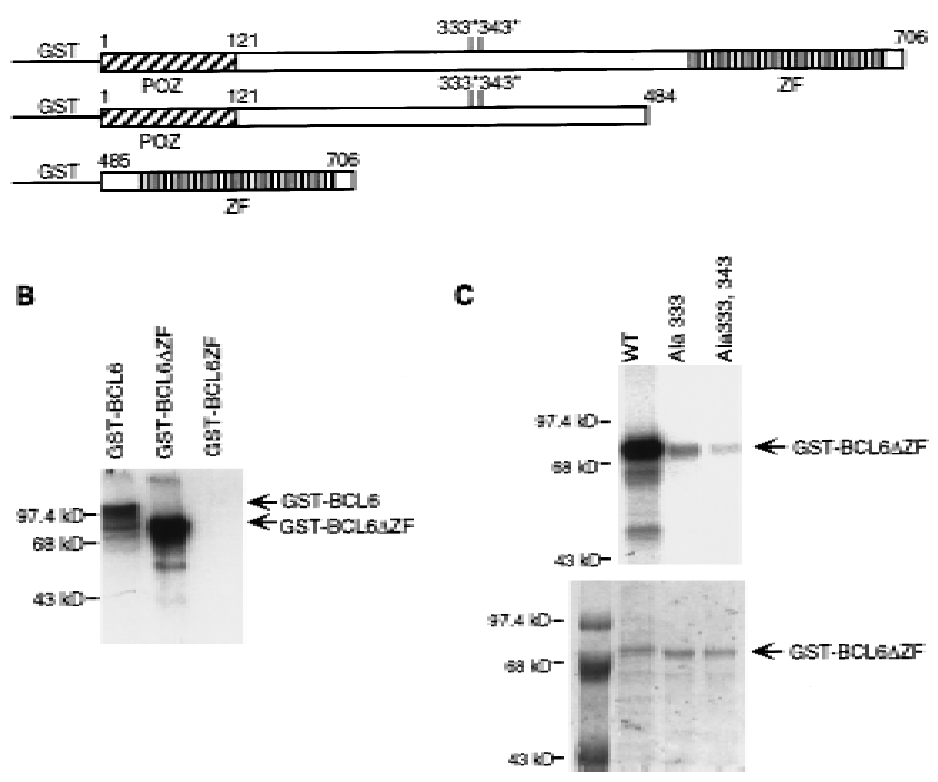
A

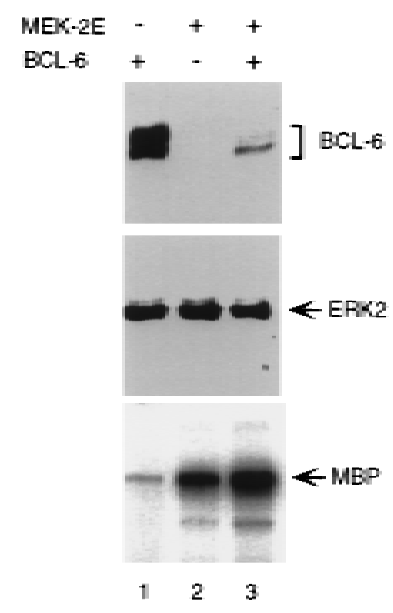

B

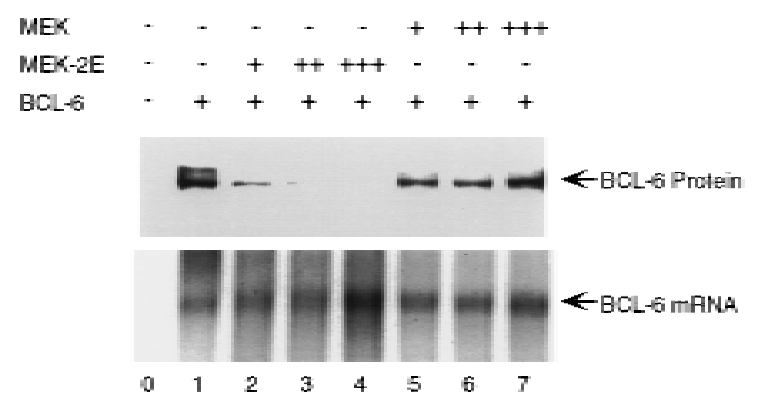

C

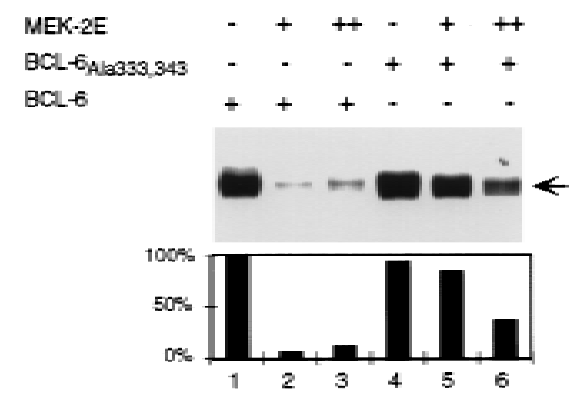

D

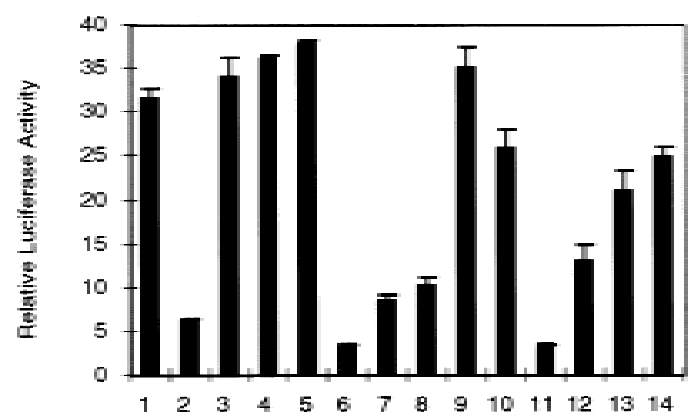

BGES-TK-LUC

BCL 6

BCL-6mas6a,345

MEK-2E

MEK

Figure 2. BCL-6 protein degradation induced by overexpression of MEK-2E in 293T cells. (A) Western blot analysis of $293 \mathrm{~T}$ cells transfected with $5 \mu \mathrm{g}$ of BCL-6 (lanes 1,3) and $5 \mu \mathrm{g}$ of M EK-2E (lanes 2,3) using anti-BCL-6 (N -70-6; top) or anti-ERK2 (C-14; middle) antibodies. (Bottom) The results of solid-phase ERK2 kinase assay performed on cell extract from the same transfectants used in the top. (B) Western blot (top) and N orthern bl ot (bottom) analysis of BCL-6 in 293T cells transfected with pM T2T-BCL-6 (BCL-6) (5 $\mu$ g) (lanes 1-7) and various amounts of M EK-2E-CMV (M EK-2E) (lanes 2-4) or M EK-CMV (M EK) (5, 10, or 15 $\mu$ g) (lanes 5-7) as indicated.

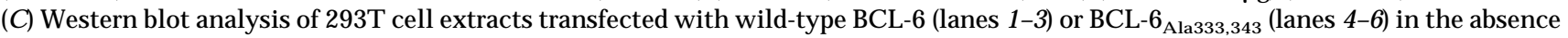
(lanes 1,4) or presence (lanes 2,3,5,6) of cotransfected M EK-2E. (Bottom) The results of densitometric scanning of the autoradiography; anal ogous results were obtained in three independent experiments. (D) Analysis of BCL-6 transrepression activity in the presence of active MEK. 293T cells were transfected with 2.0 pmole of B6BS-TK-Luc, 0.04 pmole of pM T2T-BCL-6 (Ianes 2-8) or pMT2T-BCL$6_{\text {Ala333,343 }}$ (lanes 11-14) and increasing amounts $(0.1,0.2,0.4,0.4$ pmole) of MEK-2E (lanes 3-5,9,12-14) or MEK (Ianes 6-8,10) as indicated. Cells were harvested $48 \mathrm{hr}$ after transfection and luciferase activities were measured by a luminometer.

Consistent with the MEK-2E-induced reduction in BCL-6 levels, a transient cotransfection assay in 293T cells showed that MEK-2E, but not MEK, could eliminate the transcriptional transrepressor activity of wildtype BCL-6 (Fig. 2D, lanes 3-5) on a reporter vector expressing the luciferase gene downstream to the BCL-6 DN A-binding site (B6BS) (Chang et al. 1996); the partial phosphorylation-resistant mutant BCL-6 $6_{\text {Ala333,343 }}$ was partially resistant to MEK-2E (Fig. 2D, lanes 12-14). Overall, these results indicate that MAPK activation leads to functional inactivation of BCL- 6 by causing its accel erated degradation.

BCL- 6 degradation is mediated by ubiquitin/ proteasome pathway

In examining the possible mechanisms for M APK-mediated degradation of $\mathrm{BCL}-6$, we noted that the cluster of
M APK putative phosphorylation sites are embedded in a regi on enriched in proline, glutamine, and serine, within which we identified three typical PEST sequences that score 9.4, 5.0, and 2.6, respectively (Fig. 3A; any score above zero denotes a possible PEST region; scores greater than five indicate the strongest candidates). These motifs have been demonstrated to represent targets for regulated protein degradation (Rogers et al. 1986; Rechsteiner and Rogers 1996). To determine whether MAPK-mediated BCL- 6 degradation targeted these PEST sequences, we constructed vectors expressing two epitope HAtagged bcl-6 del etion mutants (see Fig. 3A) and cotransfected them with the MEK-2E vector into 293T cells. Western blot analysis using anti-HA antibodies (Fig. 3B) showed that M EK-2E-mediated degradation targeted the amino-terminal half of the molecule and it was completely abolished in the BCL-6 $6(300-417)$ internal deletion mutant that lacks a small portion of the BCL- 6 pro- 
Figure 3. BCL-6 contains PEST sequences that are required for phosphorylation-induced degradation. (A) Schematic representation of HA-tagged BCL- 6 proteins. PEST sequences were identified by the PESTFIND program. PEST1: AA336-AA351 (KSDCQPN SPTESCSSK), score 9.4; PEST 2: AA365-AA371(KSPTDPK), score 5.0; PEST 3: AA 406-AA430 (RAYTAPPACQPPMEPEN LDLQSPTK), score 2.6. (B) 293T cells were transfected with $5 \mu \mathrm{g}$ of pMT2T vectors expressing HA-BCL-6 (Ianes 1-3), HA-BCL-6s (300-417) (lanes 46), or HA-BCL-6ZF (lanes 7-9) in the absence of MEK-2E (lanes $1,4,7$ ) or in the presence of increasing amount $(5,10 \mu \mathrm{g})$ of MEK-2E (lanes 2,5,8,3,6,9). Forty-eight hours after transfection, equal amounts of cell lysates were anal yzed (after normalization for transfection efficency based on $\beta$ gal actosi dase activity of cotransfected plasmids) by $8 \%$ SDS-PAGE and Western blot using anti-HA (12CA5) antibodies.
A

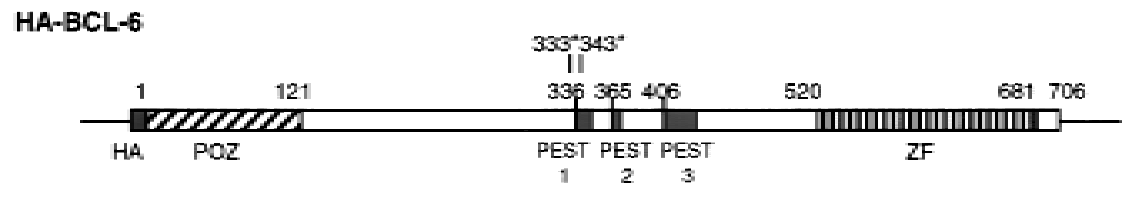

HA-BCL-6ZF

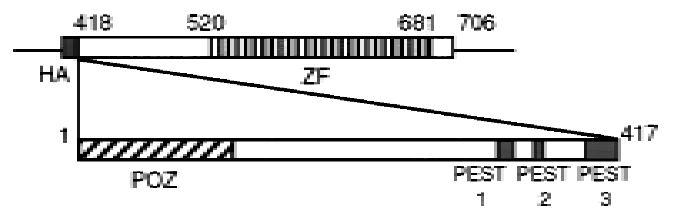

HA-BCL-64(300-417)

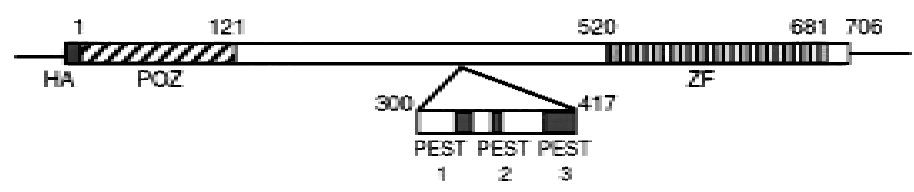

B

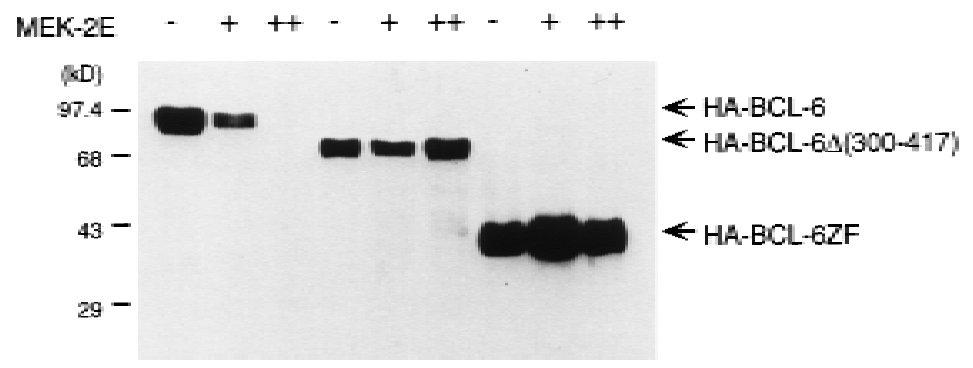

tein containing all three PEST sequences. These results indicate that MAPK-induced phosphorylation and degradation of BCL- 6 target PEST sequences located in the same domain as the MAPK phosphorylation sites.

The involvement of PEST sequences suggested that M APK-induced BCL- 6 degradation could be mediated by the ubiquitin/proteasome pathway (Hochstrasser 1996). Therefore, we tested whether MEK-2E mediated degradation of BCL-6 in transfected 293T cells could be inhibited by the proteasome inhibitor C bz-LLL (M G132) (Kim and Maniatis 1996; Palombella et al. 1994; Rock et al. 1994). Figure $4 A$ shows that $B C L-6$ degradation was completely inhibited by MG132, but not by DMSO (solvent control) or cal pain inhibitor II (CI II), a cysteine-protease inhibitor (Kim and Maniatis 1996; Palombella et al. 1994). Because the addition of multipl e ubiquitins to the proteolysis substrate is a key step preceding target degradation by the proteasome, we then tested whether BCL-6/ubiquitin conjugates in vivo could be detected. To this end, 293T cells were transfected with vectors expressing $\mathrm{BCL}-6, \mathrm{MEK}-2 \mathrm{E}$, and epitope $\left(\mathrm{His}_{6}\right)$-tagged ubiquitin in the presence or absence of MG132. Cell lysates were subjected to immunoprecipitation with antiBCL- 6 antibodies, and the immunoprecipitates were analyzed by Western blotting using anti-ubiquitin antibodies. Figure 4B shows that in the absence of M G132, low levels of BCL-6/ubiquitin were detectable when BCL-6 and ubiquitin were coexpressed with exogenous M EK-2E (lane 4); in the presence of MG132, typical ladders representing multi-ubiquitinated forms of BCL- 6 were detectabl e at high levels in the presence of M EK-2E (Iane 8); low levels were detectable also in its absence (lane 7), suggesting that the normal turnover of BCL-6 degradation may be mediated by basal levels of endogenous MAPK activity. Based on the specific pharmacological inhibition and the detection of MEK-2E-inducible BCL6/ubiquitin conjugates, we conclude that MAPK-induced phosphorylation induces degradation of $B C L-6$ via the ubiquitin/proteasome pathway.

MAPK-mediated phosphorylation and degradation of BCL-6 is induced by antigen-receptor signaling in $B$ cells

To demonstrate the physiological significance of M APKmediated phosphorylation/degradation of BCL-6 in B cells, we treated a B-cell lymphoma cell line (Ramos) with anti-IgM antibodies, a treatment that mimics B-cell antigen-receptor signaling and specifically activates MAPK (ERK2) (Gold et al. 1992; Sakata et al. 1995; Sutherland et al. 1996). As previously demonstrated, an in vitro assay showed that ERK 2 kinase activity was rapidly increased $5 \mathrm{~min}$ after anti-IgM treatment (Fig. 5A); this was followed by hyperphosphorylation of ERK2 and 
A

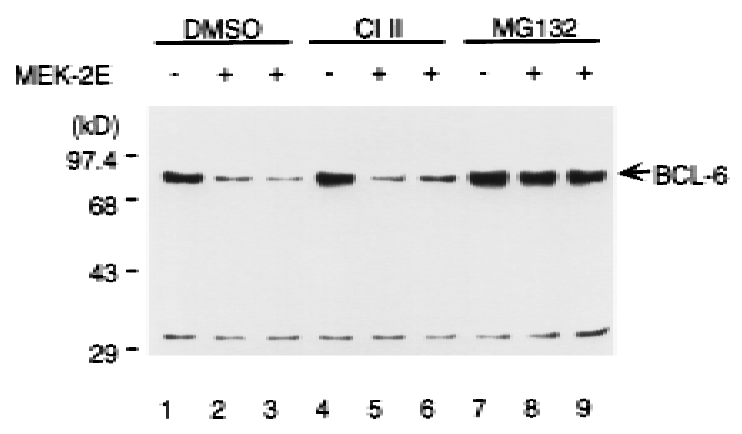

B

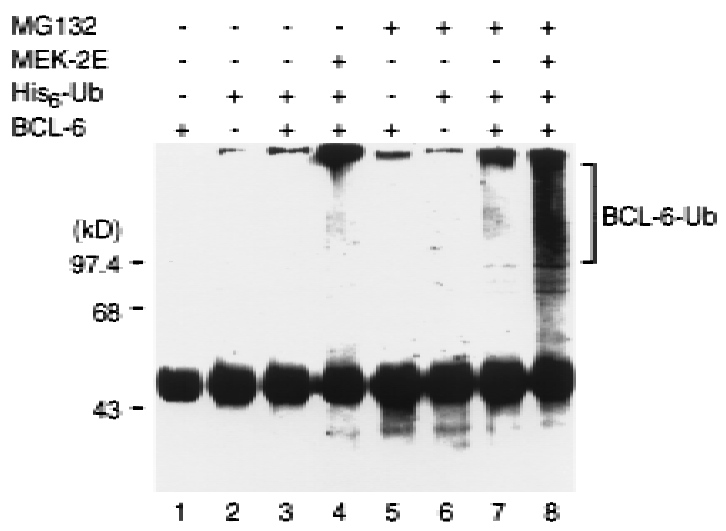

Figure 4. MAPK-induced BCL-6 degradation is mediated by the ubiquitin/proteasome pathway. (A) Western bl ot analysis of BCL- 6 proteins in 293T cells transfected with BCL- 6 in the absence or presence of cotransfected MEK-2E treated with $0.2 \%$ DMSO (lanes 1-3), 50 MM Cal pain inhibitor II (lanes 4-6), or 50 4M MG132 (lanes 7-9) (added $8 \mathrm{hr}$ after transfection). (B) 293T cells were transfected with $\mathrm{BCL}-6, \mathrm{His}_{6}-\mathrm{Ub}$, and M EK-2E in the absence (lanes 1-4) or presence of MG132 (lanes 5-8). Cell Iysates were immunoprecipitated with anti-BCL-6 antibodies ( $N$ 70-6) and the immunoprecipitants were analyzed by $6 \%$ SDSPAGE followed by Western blot analysis using anti-ubiquitin antibodies.

BCL-6 (note the slow-migrating bands in Fig. 5A) and by the disappearance of BCL-6, but not ERK2. In the same experiment, $\mathrm{N}$ orthern blot analysis showed that bcl- 6 mRN A levels did not change during anti-IgM treatment of Ramos cells (Fig. 5A, bottom). To determine whether hyperphosphorylation was associated with increased BCL- 6 instability, we analyzed the half-life of BCL-6 in anti-IgM-treated Ramos cells by a "pulse-chase" labeling experiment. The results (Fig. 5B) showed that the hyperphosphorylated (slow-migrating) forms of BCL- 6 were significantly less stable than the hypophosphorylated (fast-migrating) forms (half life 4-6 hr). Anti-IgM-induced BCL-6 degradation was dependent on phosphorylation as it was inhibited by a specific MAPK inhibitor PD 098059 (Fig. 5C) (Dudley et al. 1995; Pang et al. 1995), and was mediated by the ubiquitin/proteasome pathway since it was specifically inhibited by MG132 (Fig. 5D). Finally, anti-IgM treatment of Ramos cells stably transfected with cadmium-inducible vectors expressing $\mathrm{HA}$ tagged wild-type, 333/343 mutant, or amino-terminal deleted BCL-6 proteins showed that degradation required phosphorylation of the 333 and 343 serines as well as the amino-terminal half of BCL-6 containing the PEST motifs (Fig. 5E). These results demonstrate that MAPK-mediated phosphorylation of BCL- 6 and its degradation by the ubiquitin/proteasome pathway represent a physiologic pathway that can be activated by antigen-receptor signling in B cells.

\section{Discussion}

The present study identifies a signal transduction pathway by which the antigen receptor regulates the stability of the BCL- 6 transcription factor in B cells. The results have implications for the normal mechanism regulating GC formation as well as for the role of deregulated bcl- 6 expression in Iymphomas deriving from GC B cells. In addition, several observations suggest that MAPK-mediated regulation of POZ/Zinc finger protein stability may represent a general, highly conserved regulatory mechanism in eukaryotic cells.

\section{Regulation of BCL-6 stability during GC formation}

The finding that antigen-receptor-induced activation of MAPK leads to BCL-6 degradation must be seen in the context of the complex network of signals modulating receptor signal ing in GC B cel Is (Tedder et al . 1997; C ambier 1997). During GC formation, activation of this pathway is consistent with the observation that pre-GC B cells in the follicular mantle zone, the site where $B$ cells encounter the antigen, express bcl-6 RN A, but not the BCL-6 protein (Allman et al . 1996; Cattoretti et al. 1995). Within the GC, the coexistence of antigen and bcl- 6 expression implies that antigen-receptor signaling must be modulated by mechanisms that allow BCL-6 stability. These mechanisms may include down-regulation of antigen-receptor expression in centroblasts (MacLennan 1994), modulation of receptor signaling by CD22 or Fc $\gamma$ receptor (Tedder et al. 1997; Cambier 1997), and the activity of de-ubiquitinases (DUB), which regulate substrate ubiquitination and are induced by cytokines acting on GC B cells (Zhu et al. 1996). During post-GC differentiation, antigen-induced degradation may serve as a rapid mechanism to down-regulate bcl-6 expression, in synergy with transcriptional down-regulation by CD40 signaling (Allman et al. 1996; Cattoretti et al. 1997). Finally, the regulation of BCL-6 stability during GC development is likely to be affected by various additional signals that activate MAPK in B cells, including various cytokines (TN F, IL-6, IL-2) Nietor et al. 1993; Minami et al. 1994; Fukada et al. 1996). The effect of these signals on the pathway linking the antigen receptor to BCL-6 can be tested in the experimental systems used in this study.

\section{Implication for lymphomagenesis}

M ost B-cell lymphoma types, FL, DLCL, and Burkitt (BL) lymphoma, are thought to derive from the GC B cells. Although rearrangements and/or mutations of the bcl-6 
Niu et al.

A
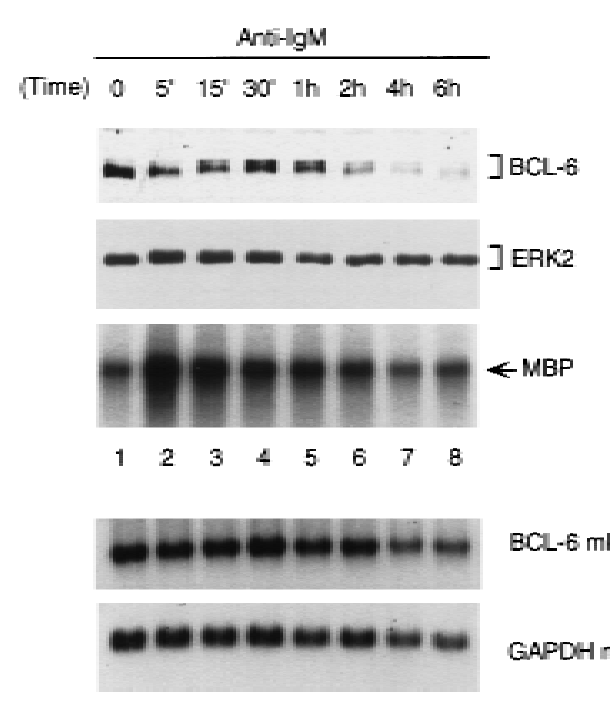

BCL-6 MFNA

GAPDH mANA

B

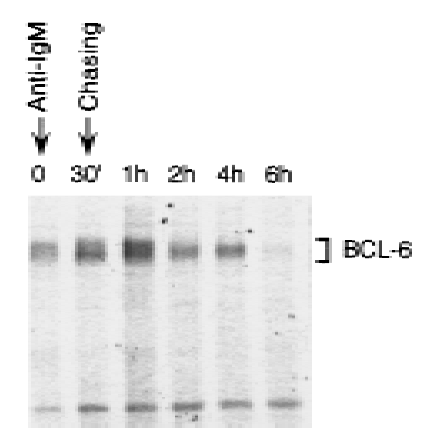

c

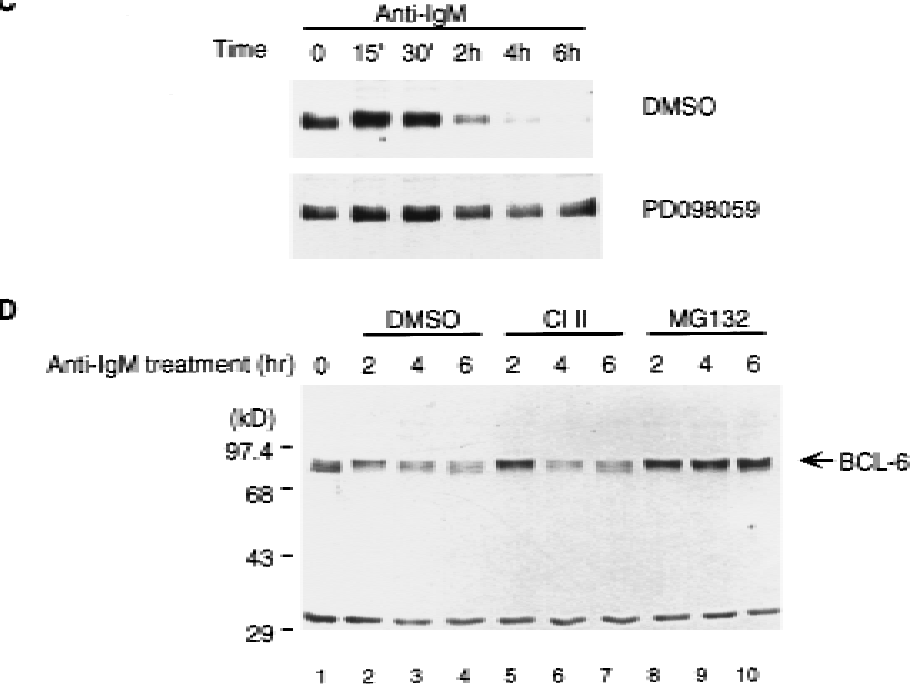

E

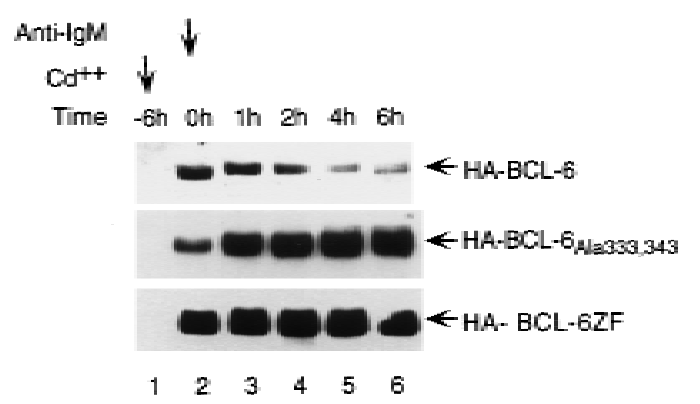

Figure 5. BCL-6 is phosphorylated and degraded by antigen-receptor signaling in B cells. Ramos cells $\left(1 \times 10^{6} / \mathrm{ml}\right)$ were treated with anti-IgM $(10 \mu \mathrm{g} / \mathrm{ml})$ and harvested at different time points after treatment as indicated. (A) (Top three panels) Equal amounts of cell extracts were used for Western bl ot analysis using anti-BCL-6 (top), or anti-ERK2 (middle) antibodies, and for solid-phase ERK2 kinase assays (M BP, bottom). Equal amounts of RN As $(10 \mu \mathrm{g})$ were used for N orthern blot analysis with BCL-6 or GAPDH probes (bottom). (B) Hyperphosphorylated BCL-6 proteins are more unstable. Ramos cells were pulse labeled for $1 \mathrm{hr}$ with [ $\left.{ }^{35} \mathrm{~S}\right] \mathrm{methionine}$ and $\left[{ }^{35}\right.$ S]cysteine, and then treated with anti-lgM $(10 \mu \mathrm{g} / \mathrm{ml})$ for $30 \mathrm{~min}$ and subsequently incubated in the presence of an excess of nonradioactive methionine and cysteine for the indicated times (chase). Cell extracts were immunoprecipitated with anti-BCL-6 antibodies and analyzed by SDS-PAGE followed by autoradiography. (C) Anti-IgM induced BCL-6 phosphorylation and degradation is prevented by a specific MEK inhibitor. Western blot analysis of BCL- 6 in Ramos cells treated with anti-IgM in the presence of $0.2 \%$ DMSO or 50 MM PD098059 (added 30 min before anti-IgM treatment). (D) Anti-IgM induced BCL-6 degradation is prevented by a specific proteasome inhibitor. Western blot analysis of BCL-6 in Ramos cells treated with anti-IgM in the presence of $0.2 \%$ DMSO (lanes 2-4), $50 \mu \mathrm{M}$ Cal pain inhibitor II (lanes 5-7), and $50 \mu \mathrm{M}$ M G132 (lanes 8-10) (added $1 \mathrm{hr}$ before the treatment). (E) M utant BCL-6 proteins are resistant to anti-IgM-induced degradation. Ramos cells stably transfected with pHeBo-MT-HA-BCL6, pHeBo-MT-HA$\mathrm{BCL}-6_{\mathrm{Ala333,343}}$ and pHeBo-MT-HA-BCL6ZF were treated with $1 \mu \mathrm{M} \mathrm{CdCl}{ }_{2}$ for $6 \mathrm{hr}$ to induce exogenous BCL- 6 expression. Cells were then treated wth anti-lgM $(10 \mu \mathrm{g} / \mathrm{ml})$ and harvested at different time points as indicated. Equal amounts of cell extracts were loaded

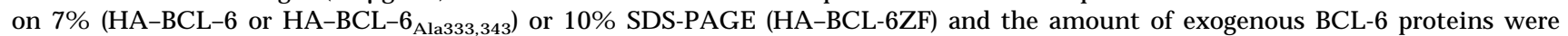
analyzed by Western blot using anti-HA antibodies (12CA5).

regulatory region are found most frequently in DLCL and FL, all GC-derived lymphomas, including those carrying a structurally normal bcl- 6 gene, express the BCL-6 protein (Cattoretti et al. 1995). This implies that the BCL-6 protein is stable in tumor cells and suggests that MAPKmediated degradation may be blocked by genetic or epigenetic alterations affecting the pathway leading to BCL-6 degradation. The observation that BCL-6 degradation can be triggered from the cell surface by activation of the antigen receptor has potential relevance for the therapy of B-cell lymphoma.
MAPK-mediated regulation of POZ/zinc finger transcription factors

MAPK is a ubiquitous, evolutionarily conserved signal transducer that is activated by heterogeneous signals that originate from the cell membrane and are transduced to MAPK via RAS proteins (Gold and Matsuuchi 1995; Alberola-lla et al. 1997). Accordingly, POZ/zinc finger proteins represent a large family of highly conserved transcription factors including Drosophila cell fate regulators such as Tramtrack and Broad-compl ex, as 
well as human cancer-associated proteins such as BCL-6 and PLZF. These molecules have strong structural (POZ and ZF domains), as well as functional homologies being transcriptional repressors that control cell differentiation (Chen et al. 1994; Emery et al. 1994; Albagli et al. 1995). M ost notably, POZ/zinc finger proteins al so carry possible MAPK phosphorylation sites and PEST sequences in approximatel y the same position as those carried by $\mathrm{BCL}-6(\mathrm{H}$. Niu et al., unpubl.). In Drosophila, degradation of TTK88, a POZ/zinc finger inhibitor of neural-cell differentiation, has been shown to be mediated by MAPK (Li et al. 1997; Tang et al. 1997). Thus, degradation of POZ/zinc finger transcription factors may represent a general mechanism by which the RAS/ MAPK pathway controls cell function and differentiation.

\section{Materials and methods}

Reagents and plasmids

Goat anti-human IgM ( $\mu$-heavy chain specific) was obtained from Southern Biotechnology. Polyclonal anti-BCL-6 (N-70-6) antiserum was produced by using the amino-terminal peptides of BCL-6 (Cattoretti et al. 1995). Monoclonal mouse anti-ERK2 (C-14) was purchased from Santa Cruz Biothechnology (Santa Cruz, CA). Monoclonal mouse anti-ubiquitin was obtained from Zymed Laboratories (South San Francisco, CA). M onoclonal mouse anti-HA (12CA5) was purchased from Boehringer Mannheim, as was Calpain Inhibitor II. Protein A-Sepharose $\mathrm{CL}-4 \mathrm{~B}$ and glutathione-Sepharose were purchased from Pharmacia. M yelin basic protein (M BP) and N-CBZ-Leu-Leu-Leu-AL (M G 132) were obtained from Sigma. PD 098059 was purchased from Calbiochem-N ovabiochem (La Jolla, CA). The GSTBCL6, GST-BCL6 ZZF， GST-BCL6ZF， GST-BCL6 ZF $_{\text {Alаззз, }}$ and GST-BCL6 $6 \Delta \mathrm{ZF}_{\mathrm{Al} \text { аз33,343 }}$ fusion proteins were produced by pGEX-2TK-based plasmids (Pharmacia Biotech) containing fulllength, del etion, or point mutants of bcl-6. The point mutations (Ala333, Ala343) were generated by PCR-based methods; the sequence of the resulting plasmids was confirmed by nucleotide sequence analysis. pMT2T-BCL-6 and B6BS-TK-LUC have been described as previous (Chang et al. 1996). pMT2T-BCL$6_{\text {Ala333,343 }}$ was constructed by transferring the Bcll-Ncol fragments of plasmid pGEX-2TK-BCL6 $\Delta \mathrm{ZF}_{\mathrm{Ala333,343}}$ into the pMT 2T-BCL-6 vector. MEK-2E-EE-CMV and MEK-EE-CMV for expressing of constitutively active or inactive MEK were provided by Dr. D. Templeton (Case Western Reserve University, Cleveland, OH). The pMT2T-HA-BCL-6, pMT2T-HABCL-6 $(300-417)$, and PMT2T-HA-BCL-6ZF vectors were constructed by inserting the sequences encoding the $\mathrm{HA}$ epitope upstream and in frame with bcl- 6 coding sequences. Deletion mutants of bcl- 6 were produced by PCR-based methods and confirmed by sequencing. $\mathrm{His}_{6}$-ubiquitin-CMV was kindly provided by $T$. Maniatis (Harvard Medical School, Boston, MA). Episomally replicating plasmid pHeBo-MT, which carries EBV oriP, hygromycin $B$, and MT promoter efficiently yields hygromycin-resistant colonies.

\section{ERK2 kinase assays}

BCL-6 GST fusion proteins were purified using glutathioneSepharose beads as suggested by the manufacturer (Pharmacia Biotech). Recombinant ERK2 (N ew England Biolabs) assays were performed as suggested by the manufacturer using purified wild-type and mutant GST fusion proteins as substrates. In solid-phase ERK2 kinase assays, cells were lysed in ice-cold lysis buffer (50 mM Tris at pH 7.5, 10\% glycerol, 1\% Triton X-100, $150 \mathrm{~mm} \mathrm{NaCl}, 100 \mathrm{~mm} \mathrm{~N} \mathrm{aF}, 5 \mu \mathrm{M} \mathrm{ZnCl}_{2}, 1 \mathrm{~mm} \mathrm{Na} \mathrm{VO}_{4}, 10 \mathrm{~mm}$ EGTA, $2 \mathrm{~mm}$ PMSF, $1 \mu \mathrm{g} / \mathrm{ml}$ aprotinin, $1 \mu \mathrm{g} / \mathrm{ml}$ leupeptin, and $1 \mu \mathrm{g} / \mathrm{ml}$ pepstatin) and centrifuged at $100,000 \mathrm{~g}$ for $15 \mathrm{~min}$ at $4^{\circ} \mathrm{C}$. The supernatant $(250-500 \mu \mathrm{g}$ cellular protein) was then immunopreci pitated using anti-ERK2 anti bodies (C-14) and protein A-Sepharose CL-4B. Beads were washed three times with lysis buffer and once with kinase buffer $(50 \mathrm{~mm}$ Tris at $\mathrm{pH}$ 7.5,

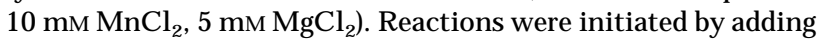
$50 \mu \mathrm{l}$ kinase buffer containing substrate MBP, $5 \mu \mathrm{M}$ ATP, and 5 $\mu \mathrm{Ci}\left[\gamma^{-32} \mathrm{P}\right] \mathrm{ATP}$. After $15 \mathrm{~min}$ at $37^{\circ} \mathrm{C}$, reactions were terminated by adding $2 \times$ SDS-PAGE sample buffer. Samples were electrophoresed on 15\% SDS-polyacrylamide gels which were then dried and analyzed by autoradiography.

\section{Cell transfection}

293T cells, grown in DMEM, 10\% FBS, were transfected transiently with various DN A vectors using standard cal cium phosphate precipitation methods. Ramos cells, grown in IMDM, $10 \% \mathrm{FBS}$, were transfected stably with the plasmid pHeBo-MTHA-BCL-6, pHeBo-MT-HA-BCL-6 Ala333,343 $_{1}$ and the deletionmutant construct pHeBo-M T-HA-BCL-6ZF by electroporation followed by selection in hygromycin B $(400 \mu \mathrm{g} / \mathrm{ml})$. HA-bcl-6 gene expression under control of the metal lothionein (MT) promoter were induced by adding $1 \mu \mathrm{m}$ of $\mathrm{CdCl}_{2}$.

\section{Northern and Western blot analysis}

Total RNA were isolated from cells by using Trizol-reagents (GIBCO-BRL) and equal amounts of RN A were separated on 1\% formal dehyde-agarose gel. Northern blot analysis was performed by using standard methods with full-length bcl-6 cDN A as probes and normalized by GAPDH hybridization. Whole-cell lysates were prepared by lysing cells in RIPA buffer with $2 \mathrm{mM}$ PMSF, $1 \mu \mathrm{g} / \mathrm{ml}$ aprotinin, $1 \mu \mathrm{g} / \mathrm{ml}$ of leupeptin, $1 \mu \mathrm{g} / \mathrm{ml}$ pepstatin, $1 \mathrm{~mm} \mathrm{Na} \mathrm{VO}_{4}, 5 \mathrm{~mm} \mathrm{NaF}$, and $10 \mathrm{~mm} \beta$-glycerophosphate. For transient transfectants, protein amounts loaded on gel were normalized by transfection efficiency ( $\beta$-gal activity). For Ramos cells and their stable transfectants (untreated or treated), equal amounts of protein were analyzed by $8 \%$ or $10 \%$ SDS-PAGE, and subsequently by Western blot analysis using anti-BCL-6 (N-70-6), anti-ERK2 (C-14), or anti-HA (12CA5) antibodies at 1:3000, 1:1000, or 1:500 dilutions. The results were visualized by ECL (Amersham).

\section{In vivo ubiquitination assay}

293T cells were transfected transiently with pMT2T-BCL-6, $\mathrm{His}_{6}$-ubiquitin-CMV, and MEK-2E-CMV vectors as indicated. MG132 $(50 \mu \mathrm{M})$ was added $8 \mathrm{hr}$ after transfection. The total amount of transfected DNA was kept constant in all experiments by adding empty vector. Twenty-four hours after transfection, cells were lysed in RIPA buffer with $10 \mathrm{~mm} \mathrm{~N}$-ethylmaleimide and various protease inhibitors as described (Pagano et al. 1995). The cell lysates were then immunoprecipitated using anti-BCL- 6 antibodies. The immunopreci pitates were loaded on $6 \%$ SDS-PAGE and processed for Western blot analysis using the anti-ubiquitin antibodies (Zymed) at 1:1000 dilution as described (Avantaggiati et al. 1996).

\section{Pulse-chase labeling experiment}

Ramos cells $\left(12 \times 10^{7}\right)$ were collected by centrifugation, washed in PBS, resuspended in $100 \mathrm{ml}$ of DMEM without methionine 
and cysteine (GIBCO-BRL), and starved for $60 \mathrm{~min}$. [ $\left.{ }^{35} \mathrm{~S}\right] \mathrm{methio-}$ nine and $\left[{ }^{35} \mathrm{~S}\right]$ cysteine $(3 \mathrm{mCi}$; ICN ) were added and pulse-labeled for $60 \mathrm{~min}$ and then treated with anti-IgM for $30 \mathrm{~min}$. Cold methionine and cysteine were then added to final concentrations of $150 \mu \mathrm{g} / \mathrm{ml}$. Cells were collected and lysed in RIPA buffer with proteinase and phosphatase inhibitors. The cell extracts, adjusted for equal cpm, were immunoprecipitated with anti-BCL-6 antibodies, and analyzed by SDS-PAGE followed by autoradiography.

\section{Acknowledgments}

We thank D. Templeton for a gift of the MEK-2E-EE-CMV and MEK-EE-CMV plasmids; T.K. Kim, and T. Maniatis for the $\mathrm{His}_{6}$-ubiquitin-CMV plasmid; S.W. Rogers, P. Zhang, and L. Liao for help with the use of the PEST-FIND program; and S. Chellapan for hel pful discussions. This work was supported by $\mathrm{N}$ ational Institutes of Health grant CA-37295.

The publication costs of this article were defrayed in part by payment of page charges. This article must therefore be hereby marked "advertisement" in accordance with 18 USC section 1734 solely to indicate this fact.

\section{References}

Albagli, O., P. Dhordain, C. Deweindt, G. Lecocq, and D. Leprince. 1995. The $B T B / P O Z$ domain: A new protein-protein interaction motif common to DNA- and actin-binding proteins. Cell Growth \& Differ. 6: 1193-1198.

Alberola-lla, J., S. Takaki, J.D. Kerner, and R.M. Perlmutter. 1997. Differential signaling by lymphocyte antigen receptors. Annu. Rev. Immunol. 15: 125-154.

Allman, D., A. Jain, A. Dent, R.R. Maile, T. Selvaggi, M.R. Kehry, and L.M. Staudt. 1996. BCL-6 expression during B-cell activation. Blood 87: 5257-5268.

Avantaggiati, M., M. Carbone, A. Graessman, Y. Nakatani, B. Howard, and A. Levine. 1996. The SV40 large T antigen and adenovirus E1A oncoproteins interact with distinct isoforms of the transcriptional co-activator p300. EMBO J. 15: 22362248.

Bardwell, V.J. and R. Treisman. 1994. The POZ domain: A conserved protein-protein interaction motif. Genes \& Dev. 8: 1664-1677.

Baron, B.W., G. N ucifora, N. M cCabe, R. Espinosa, B.M. Le, and T.W. M CKeithan. 1993. Identification of the gene associated with the recurring chromosomal translocations $\mathrm{t}(3 ; 14)(q 27 ; q 32)$ and $\mathrm{t}(3 ; 22)(\mathrm{q} 27 ; \mathrm{q11})$ in B-cell Iymphomas. Proc. Natl. Acad. Sci. 90: 5262-5266.

Bastard, C., C. Deweindt, J.P. Kerckaert, B. Lenormand, A. Rossi, F. Pezzella, C. Fruchart, C. Duval, M. Monconduit, and H. Tilly. 1994. LAZ3 rearrangements in non-Hodgkin's Iymphoma: Correlation with histology, immunophenotype, karyotype, and clinical outcome in 217 patients. Blood 83: 2423-2427.

Cambier, J.C. 1997. Positive and negative signal co-operativity in the immune system: The BCR, Fc gamma RIIB, CR2 paradigm. Biochem. Soc. Trans. 25: 441-445.

Cattoretti, G., C.C. Chang, K. Cechova, J. Zhang, B.H. Ye, B. Falini, D.C. Louie, K. Offit, R.S. Chaganti, and R. DallaFavera. 1995. BCL-6 protein is expressed in germinal-center B cells. Blood 86: 45-53.

Cattoretti, G., J. Zhang, A.M. Cleary, S. Lederman, G. Gaidano, A. Carbone, R.S.K. Chaganti, and R. Dalla-Favera. 1997. Downregulation of BCL-6 gene expression by CD 40 and EBV latent membrane protein-1 (LMP1) and its block in lym- phoma carrying BCL-6 rearrangements. (Suppl. I) Blood 90: p175a.

Chang, C.C., B.H. Ye, R.S. Chaganti, and R. Dalla-Favera. 1996. BCL-6, a POZ/zinc-finger protein, is a sequence-specific transcriptional repressor. Proc. Natl. Acad. Sci. 93: 69476952.

Chardin, P., G. Courtois, M.G. Mattei, and S. Gissel brecht. 1991. The KUP gene, located on human chromosome 14, encodes a protein with two distant zinc fingers. Nucleic Acids Res. 19: 1431-1436.

Chen, Z., N .J. Brand, A. Chen, S.J. Chen, J.H. Tong, Z.Y. Wang, S. Waxman, and A. Zelent. 1993. Fusion between a novel Kruppel-like zinc finger gene and the retinoic acid receptoral pha locus due to a variant $t(11 ; 17)$ translocation associated with acute promyelocytic leukaemia. EMBO J. 12: 1161-1167.

Chen, Z., F. Guidez, P. Roussel ot, A. Agadir, S.J. Chen, Z.Y. Wang, L. Degos, A. Zelent, S. Waxman, and C. Chomienne. 1994. PLZF-RAR al pha fusion proteins generated from the variant $\mathrm{t}(11 ; 17)(\mathrm{q} 23 ; \mathrm{q} 21)$ translocation in acute promyelocytic leukemia inhibit ligand-dependent transactivation of wild-type retinoic acid receptors. Proc. Natl. Acad. Sci. 91: 1178-1182.

Chen, W., S. Iida, D.C. Louie, R. Dalla-Favera, and R.S.K. Chaganti. 1998. Heterol ogous promoters fused to BCL-6 by chromosomal translocations affecting band $3 q 27$ cause its deregulated expression during B-cell differentiation. Blood 91: 603-607.

Dalla-Favera, R., B.H. Ye, G. Cattoretti, F. Lo Coco, C.C. Chang, J. Zhang, A. Migliazza, K. Cechova, H. Niu, S. Chaganti, W. Chen, D.C. Louie, K. Offit, and R.S. Chaganti. 1996. BCL-6 in diffuse large-cell lymphomas. In Important advances in oncology (ed. V.T. DeVita, S. Hellman, and S.A. Rosenberg), pp. 139-148. Lippincott-Raven Publishers, Philadel phia, PA.

Dent, A.L., A.L. Shaffer, X. Yu, D. Allman, and L.M. Staudt. 1997. Control of inflammation, cytokine expression, and germinal center formation by BCL-6. Science 276: 589-592.

Deweindt, C., O. Albagli, F. Bernardin, P. Dhordain, S. Qui ef, D. Lantoine, J.P. Kerckaert, and D. Leprince. 1995. The LAZ3/ BCL6 oncogene encodes a sequence-specific transcriptional inhibitor: A novel function for the BTB/POZ domain as an autonomous repressing domain. Cell Growth \& Differ. 6: 1495-1503.

DiBello, P.R., D.A. Withers, C.A. Bayer, J.W. Fristrom, and G.M. Guild. 1991. The Drosophila Broad-Complex encodes a family of related proteins containing zinc fingers. Genetics 129: 385-397.

Dudley, D.T., L. Pang, S.J. Decker, A.J. Bridges, and A.R. Saltiel. 1995. A synthetic inhibitor of the mitogen-activated protein kinase cascade. Proc. Natl. Acad. Sci. 92: 7686-7689.

Emery, I.F., V. Bedian, and G.M. Guild. 1994. Differential expression of Broad-Complex transcription factors may forecast tissue-specific developmental fates during Drosophila metamorphosis. Development 120: 3275-3287.

Fukada, T., M. Hibi, Y. Yamanaka, M. Takahashi-Tezuka, Y. Fujitani, T. Yamaguchi, K. N akajima, and T. Hirano. 1996. Two signals are necessary for cell proliferation induced by a cytokine receptor gp130: Involvement of STAT3 in antiapoptosis. Immunity 5: 449-460.

Gaidano, G., A. Carbone, C. Pastore, D. Capello, A. Migliazza, A. Gloghini, S. Roncella, M. Ferrarini, G. Saglio, and R. Dalla-Favera. 1997. Frequent mutation of the $5^{\prime}$ noncoding region of the BCL- 6 gene in acquired immunodeficiency syndromerelated non-Hodgkin's lymphomas. Blood 89: 37553762.

Gold, M.R. and L. Matsuuchi. 1995. Signal transduction by the 
antigen receptors of $\mathrm{B}$ and $\mathrm{T}$ Iymphocytes. Int. Rev. Cytol. 157: 181-276.

Gold, M.R., J.S. Sanghera, J. Stewart, and S.L. Pelech. 1992. Selective activation of p42 mitogen-activated protein (MAP) kinase in murine $B$ lymphoma cell lines by membrane immunoglobulin cross-linking. Evidence for protein kinase $C$ independent and -dependent mechanisms of activation. Biochem. J. 287: 269-276.

Harrison, S.D. and A.A. Travers. 1990. The Tramtrack gene encodes a Drosophila finger protein that interacts with the $\mathrm{ftz}$ transcriptional regulatory region and shows a novel embryonic expression pattern. EMBO J. 9: 207-216.

Hochstrasser, M. 1996. Ubiquitin-dependent protein degradation. Annu. Rev. Genet. 30: 405-439.

Kerckaert, J.P., C. Deweindt, H. Tilly, S. Quief, G. Lecocq, and C. Bastard. 1993. LAZ3, a novel zinc-finger encoding gene, is disrupted by recurring chromosome $3 q 27$ translocations in human Iymphomas. Nature Genet. 5: 66-70.

Kim, T.K. and T. Maniatis. 1996. Regulation of interferongamma-activated ST AT 1 by the ubiquitin-proteasome pathway. Science 273: 1717-1719.

Koonin, E.V., T.G. Senkevich, and V.I. Chernos. 1992. A family of DNA virus genes that consists of fused portions of unrelated cellular genes. Trends Biochem. Sci. 17: 213-214.

Li, S., Y. Li, R.W. Carthew, and Z.-C. Lai. 1997. Photoreceptor cell differentiation requires regulated proteolysis of the transcriptional repressor Tramtrack. Cell 90: 469-478.

LoCoco, C.F., B.H. Ye, F. Lista, P. Corradini, K. Offit, D.M. Knowles, R.S. Chaganti, and R. Dalla-Favera. 1994. Rearrangements of the BCL6 gene in diffuse large cell nonHodgkin's lymphoma. Blood 83: 1757-1759.

MacLennan, I.C. 1994. Germinal centers. Annu. Rev. Immunol. 12: 117-139.

Migliazza, A., S. Martinotti, W. Chen, C. Fusco, B.H. Ye, D.M. Knowles, K. Offit, R.S. Chaganti, and R. Dalla-Favera. 1995. Frequent somatic hypermutation of the $5^{\prime}$ noncoding region of the BCL6 gene in B-cell Iymphoma. Proc. Natl. Acad. Sci. 92: 12520-12524.

Miki, T., N. Kawamata, S. Hirosawa, and N. Aoki. 1994. Gene involved in the 3q27 translocation associated with B-cell lymphoma, BCL5, encodes a Kruppel-like zinc-finger protein. Blood 83: 26-32.

Minami, Y., I. Oishi, Z.J. Liu, S. N akagawa, T. Miyazaki, and T. Taniguchi. 1994. Signal transduction mediated by the reconstituted IL-2 receptor. Evidence for a cell type-specific function of IL-2 receptor beta-chain. J. Immunol. 152: 56805690.

M oriyama, M ., T. Yamochi, K. Semba, T. Akiyama, and S. M ori. 1997. BCL-6 is phosphorylated at multiple sites in its serineand proline-clustered region by mitogen-activated protein kinase (M APK) in vivo. Oncogene 14: 2465-2474.

Onizuka, T., M. M oriyama, T. Y amochi, T. Kuroda, A. Kazama, N. Kanazawa, K. Sato, T. Kato, H. Ota, and S. Mori. 1995. BCL-6 gene product, a 92- to 98-kD nuclear phosphoprotein, is highly expressed in germinal center $B$ cells and their neoplastic counterparts. Blood 86: 28-37.

Otsuki, T., T. Yano, H.M. Clark, C. Bastard, J.P. Kerckaert, E.S. Jaffe, and M. Raffeld. 1995. Analysis of LAZ3 (BCL-6) status in B-cell non-Hodgkin's lymphomas: Results of rearrangement and gene expression studies and a mutational analysis of coding region sequences. Blood 85: 2877-2884.

Pagano, M., S.W. Tam, A.M. Theodoras, P. Beer-Romero, G. Del Sal, V. Chau, P.R. Yew, G.F. Draetta, and M. Rolfe. 1995. Role of the ubiquitin-proteasome pathway in regulating abundance of the cyclin-dependent kinase inhibitor p27. Science 269: 682-685.
Palombella, V.J., O.J. Rando, A.L. Goldberg, and T. Maniatis. 1994. The ubiquitin-proteasome pathway is required for processing the N F-kappa B1 precursor protein and the activation of N F-kappa B. Cell 78: 773-785.

Pang, L., T. Sawada, S.J. Decker, and A.R. Saltiel. 1995. Inhibition of MAP kinase kinase blocks the differentiation of PC12 cells induced by nerve growth factor. J. Biol. Chem. 270: 13585-13588.

Rechsteiner, M. and S.W. Rogers. 1996. PEST sequences and regulation by proteolysis. Trends Biochem. Sci. 21: 267-271.

Rock, K.L., C. Gramm, L. Rothstein, K. Clark, R. Stein, L. Dick, D. Hwang, and A.L. Goldberg. 1994. Inhibitors of the proteasome block the degradation of most cell proteins and the generation of peptides presented on MHC class I molecules. Cell 78: 761-771.

Rogers, S., R. Wells, and M. Rechsteiner. 1986. Amino acid sequences common to rapidly degraded proteins: The PEST hypothesis. Science 234: 364-368.

Sakata, N., H.R. Patel, N. Terada, A. Aruffo, G.L. Johnson, and E.W. Gelfand. 1995. Selective activation of c-Jun kinase mitogen-activated protein kinase by CD 40 on human B cells. J. Biol. Chem. 270: 30823-30828.

Seyfert, V.L., D. Allman, Y. He, and L.M. Staudt. 1996. Transcriptional repression by the proto-oncogene BCL-6. Oncogene 12: 2331-2342.

Sutherland, C.L., A.W. Heath, S.L. Pelech, P.R. Young, and M .R. Gold. 1996. Differential activation of the ERK, JNK, and p38 mitogen-activated protein kinases by CD40 and the B cell antigen receptor. J. Immunol. 157: 3381-3390.

Tang, A.H., T.P. N eufeld, E. Kwan, and M. Rubin. 1997. PHYL acts to down-regulate TTK88, a transcriptional repressor of neuronal cell fates, by a SINA-dependent mechanism. Cell 90: 459-467.

Tedder, T.F., J. Tuscano, S. Sato, and J.H. Kehrl. 1997. CD22, a $B$ lymphocyte-specific adhesion molecule that regulates antigen receptor signaling. Annu. Rev. Immunol. 15: 481-504.

Vietor, I., P. Schwenger, W. Li, J. Schlessinger, and J. Vilcek. 1993. Tumor necrosis factor-induced activation and increased tyrosine phosphorylation of mitogen-activated protein (MAP) kinase in human fibroblasts. J. Biol. Chem. 268: 18994-18999.

Xue, F. and L. Cooley. 1993. Kelch encodes a component of intercellular bridges in Drosophila egg chamber. Cell 72: 681693.

Yan, M. and D.J. Templeton. 1994. Identification of 2 serine residues of MEK-1 that are differentially phosphorylated during activation by raf and MEK kinase. J. Biol. Chem. 269: 19067-19073.

Ye, B.H., G. Cattoretti, Q. Shen, J. Zhang, N. Hawe, R. Waard, C. Leung, M. Nouri-Shirazi, A. Orazi, R.S.K. Chaganti, P. Rothman, A.M. Stall, P.P. Pandolfi, and R. Dalla-Favera. 1997. The BCL-6 proto-oncogene controls germinal-centre formation and Th2-type inflammation. Nature Genet. 16: $161-170$.

Ye, B.H., S. Chaganti, C.C. Chang, H. Niu, P. Corradini, R.S. Chaganti, and R. Dalla-Favera. 1995. Chromosomal translocations cause deregulated BCL6 expression by promoter substitution in B cell lymphoma. EMBO J. 14: 6209-6217.

Ye, B.H., F. Lista, F. Lo Coco, D.M. Knowles, K. Offit, R.S. Chaganti, and R. Dalla-Favera. 1993. Alterations of a zinc finger-encoding gene, BCL-6, in diffuse large-cell lymphoma. Science 262: 747-750.

Zhu, Y., M. Carroll, F.R. Papa, M. Hochstrasser, and A.D. D'A ndrea. 1996. DUB-1, a deubiquitinating enzyme with growth-suppressing activity. Proc. Natl. Acad. Sci. 93: 32753279. 


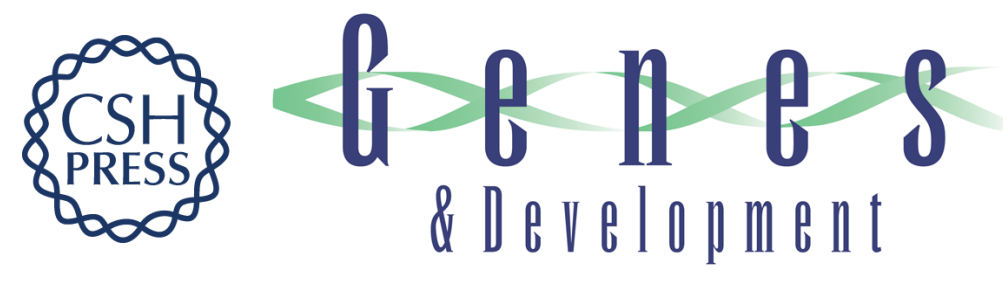

\section{Antigen receptor signaling induces MAP kinase-mediated phosphorylation and degradation of the BCL-6 transcription factor}

Huifeng Niu, Bihui H. Ye and Riccardo Dalla-Favera

Genes Dev. 1998, 12:

Access the most recent version at doi:10.1101/gad.12.13.1953

References This article cites 55 articles, 32 of which can be accessed free at:

http://genesdev.cshlp.org/content/12/13/1953.full.html\#ref-list-1

License

Email Alerting Receive free email alerts when new articles cite this article - sign up in the box at the top Service right corner of the article or click here.

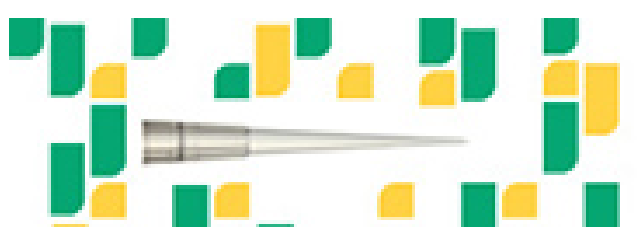

Focused on your science. 